\title{
MÍDIA E JOGOS PARALÍMPICOS NO BRASIL: INVESTIGANDO ESTIGMAS NA COBERTURA JORNALÍSTICA DA FOLHA DE S. PAULO
}

\author{
MEDIA AND PARALYMPIC GAMES IN BRAZIL: INVESTIGATING STIGMAS IN \\ FOLHA DE S. PAULO'S COVERAGE
}

\section{MEDIOS Y JUEGOS PARALIMMICOS EN BRASIL: PROFUNDIZANDO ESTIGMAS EN LA COBERTURA PERIODÍSTICA DE LA FOLHA DE S. PAULO}

\author{
Bianca Natália Poffo*, Amanda Paola Velasco*, André Guths Kugler*, \\ Sabrina Furtado*, Silvan Menezes dos Santos*, Antonio Luis Fermino*, \\ Doralice Lange de Souza*
}

\section{Palavras chave:}

Atletas.

Estigma social. Artigo de jornal.
Keywords:

Athletes.

Social stigma.

Newspaper article.
Palabras clave:

Atletas.

Estigma social.

Artículo de

periódico.
Resumo: 0 objetivo deste trabalho foi investigar se a Folha de $S$. Paulo, durante as edições dos Jogos Paralímpicos de 1992 a 2012, reproduziu narrativas apontadas pela literatura como inapropriadas e/ou estigmatizantes para se referir a atletas paralímpicos. Em uma pesquisa de cunho qualitativo e caráter descritivo, mapeamos o conteúdo das notícias para identificar passagens que estivessem relacionadas com as seguintes características: supercrip; trivialização; infantilização; vitimização. A cobertura midiática da Folha, em parte, "vitimizou" os atletas ao enfatizar fatos tristes da vida deles associados às deficiências. Também reproduziu as narrativas do supercrip, nas quais as notícias, ou parte delas, enfocaram histórias de superação de barreiras relacionadas com as deficiências dos atletas em detrimento da valorização de seus feitos esportivos. A Folha também noticiou fatos triviais sobre a vida dos atletas, como relacionamentos afetivos, questões familiares e financeiras. Houve poucos casos de "infantilização" dos atletas, contrariando achados de pesquisas internacionais.

Abstract: This study investigates whether the Brazilian newspaper Folha de S. Paulo, during the editions of the Paralympic Games from 1992 to 2012, reproduced narratives pointed out by literature as inappropriate and/or stigmatizing when referring to the Paralympic athletes. Using a qualitative and descriptive approach, we have mapped the news to identify excerpts related to the following characteristics: supercrip; trivialization; infantilization; victimization. The coverage partly "victimized" athletes by emphasizing sad facts of their lives associated with their disabilities. It also reproduced supercrip narratives in which news or part of them focused on stories about overcoming barriers by athletes related to their disabilities rather than underscoring their sporting achievements. The newspaper also reported trivial facts about athletes' lives such as romantic relationships, family and financial issues. There were a few cases of "infantilization", which contradicted international research findings.

Resumen: El objetivo del estudio fue investigar si el diario Folha de $S$. Paulo, durante las ediciones de los Juegos Paralímpicos de 1992 a 2012, reprodujo narrativas señaladas por la literatura como no apropiadas y/o estigmatizantes para referirse a atletas paralímpicos. En una investigación cualitativa y descriptiva hemos mapeado el contenido de las noticias para identificar trechos con las siguientes características: super-crip (pobrecitos-superhéroes); trivialización; infantilización; victimización. La cobertura de la Folha de São Paulo, hasta cierto punto, "victimizó" a los atletas, haciendo hincapié en hechos tristes de sus vidas asociados a las discapacidades. También reprodujo las narrativas del super-crip, donde las noticias, o una parte de ellas, se centraron en historias de superación de barreras relacionadas con las deficiencias de los atletas, en vez de valorar sus logros deportivos. La Folha de São Paulo también informó sobre hechos triviales de la vida de los atletas, tales como relaciones sentimentales, familiares y financieras. Hubo pocos casos de "infantilización" de los atletas, lo que contradice resultados de investigaciones internacionales.
*Universidade Federal do Paraná. Curitiba, PR, Brasil.

E-mail: bia.poffo@ hotmail.com; amandavelasco.18@gmail.com; andrekedf@gmail.com sabrina_mfurtado@ hotmail.com; bammenezes90@gmail.com; antonioluisf@gmail.com; desouzdo@yahoo.com

Recebido em: 14-09-2016 Aprovado em: 23-10-2017

$\mathrm{DOl}:$ http://dx.doi.org/10.22456/1982-8918.67945 (c) (i) () Licence 


\section{INTRODUÇÃO'}

Os Jogos Paralímpicos (JP) colocam em destaque atletas com deficiência em busca de excelência atlética. Eles se constituem no maior evento esportivo - se não também no maior evento dentre as diferentes áreas de manifestação social - que mais atrai a atenção da sociedade para as pessoas com deficiência (HARDIN; HARDIN, 2004; MARQUES, 2016). Os Jogos Paralímpicos, portanto, têm papel fundamental sobre o modo com que a sociedade percebe as pessoas com deficiência (HARDIN; HARDIN, 2004; MARQUES, 2016; PEREIRA; MONTEIRO; PEREIRA, 2011).

Estudos sobre a relação da mídia com o esporte paralímpico (DE LÉSÉLEUC; PAPPOUS; MARCELLINI, 2009; HARDIN; HARDIN, 2003) e guias de orientações à mídia sobre como cobrir o esporte para pessoas com deficiência (BRITISH PARALYMPIC ASSOCIATION, 2012; INTERNATIONAL PARALYMPIC COMMITTEE, 2014; PAPPOUS; SOUZA, 2016) direta ou diretamente argumentam que a projeção de atletas com deficiência na mídia pode contribuir para com o reforço ou para com a desmistificação de determinadas crenças relacionadas às pessoas com deficiência. Conforme apontam De Léséleuc, Pappous e Marcellini (2009), a mídia pode promover tanto imagens positivas quanto negativas/estigmatizantes acerca das pessoas com deficiência:

Los medios de comunicación desempeñan un papel importantísimo en el proceso de estigmatización y desestigmatización de las personas discapacitadas, según el lugar que les dediquen y los textos e imágenes que produzan al respecto, los aspectos que elijan tratar o los que omitan (DE LÉSÉLEUC; PAPPOUS; MARCELLINI, 2009, p. 81).

Os atletas com deficiência são possíveis vítimas de estigmas nas interações que estabelecem na sociedade. Estigma seria uma forma de identificação de alguém, ou de um grupo social, seja pela sua aparência física, origem étnica e religiosa ou outras características, que estaria "inabilitado para a aceitação social plena" (GOFFMAN, 2012, p. 7). Ele pode ser entendido como uma forma de inferiorização dos sujeitos quando lhes são imputados supostos atributos de conotação negativa e depreciativa. Nesse sentido, a veiculação de determinados discursos sobre pessoas com deficiência, enfatizando algumas características em detrimento de outras, pode levar à estigmatização dessas pessoas. Essa relação estabelecida pela linguagem utilizada para se referir ao grupo dos sujeitos estigmatizados acaba por destruir, inclusive, a possibilidade de atenção/valorização de outros atributos que eles venham a ter (GOFFMAN, 2012).

Partindo do pressuposto de que a mídia é uma mediadora hegemônica de fenômenos da cultura (MARTÍN-BARBERO, 2009) e, portanto, pode construir e reproduzir representações sociais acerca de pessoas com deficiência, esta pesquisa teve como objetivo investigar se a Folha de S. Paulo (FSP), durante as edições dos JP no período de 1992 a 2012, reproduziu narrativas apontadas pela literatura nacional e internacional como inapropriadas e/ou estigmatizantes para se referir a atletas paralímpicos. Mais especificamente, investigamos se o jornal reproduziu as narrativas do "supercrip", "vitimização", "infantilização" e "trivialização". Estes tipos de narrativas podem ajudar a reforçar determinados estigmas e em nada contribuem para a construção de uma representação social mais positiva acerca das capacidades e potencialidades de pessoas com deficiência no contexto esportivo. 
A narrativa do supercrip, ou dos "superdeficientes", aparece em situações em que as notícias sobre os atletas são divulgadas com ênfase na superação de suas deficiências. Os atletas são noticiados como heróis que, "apesar" de suas desvantagens devido aos seus comprometimentos advindos da deficiência, conseguem superar barreiras e realizam feitos tratados como extraordinários (HARDIN; HARDIN, 2004; SILVA; HOWE, 2012).

A narrativa que denota "infantilização" remete à situações em que os atletas são reportados como crianças, dependentes e/ou frágeis. Os autores que trabalham com essa categoria observam que expressões como "garotos", "garotas", "meninas", "jovens meninas" ou diminutivos tais como "anãozinho", "bonitinha" são exemplos dela (DE LÉSÉLEUC; PAPPOUS; MARCELLINI, 2010; DUNCAN, 2006).

A categoria "vitimização" aparece quando os atletas são retratados como "vítimas" das suas deficiências (FIGUEIREDO, 2014; HARDIN; HARDIN, 2004; MARQUES et al., 2014; SCHELL; DUNCAN, 1999). Esse tipo de abordagem reforça o que alguns autores chamam de paradigma do "coitadinho", o qual se centra nas deficiências e na tragédia pessoal dos atletas, identificando-os a partir das suas deficiências (HILGEMBERG, 2014). Esse tipo de construção da notícia pode evocar sentimentos de pena e compaixão em relação aos atletas.

A narrativa denominada de "trivialização" aparece em situações em que as notícias não retratam os feitos atléticos dos desportistas ou, quando os retratam, estes ficam em segundo plano (DE LÉSÉLEUC, 2012; DUNCAN, 2006). Nesses casos, o foco é na vida cotidiana dos atletas, relacionamentos amorosos, questões familiares e/ou hábitos alimentares (DE LÉSÉLEUC; PAPPOUS; MARCELLINI, 2009). Outros exemplos de "trivialização" podem também ser observados em casos em que se enfatizam a estética, beleza, roupas, maquiagem e/ou atributos sexuais de atletas. Esse tipo de narrativa não estigmatiza os desportistas, mas em nada contribui para a construção de imagens que reforçam as capacidades esportivas dos atletas e/ou com processos de desestigmatização destes.

\section{METODOLOGIA}

Esta pesquisa é de cunho predominantemente qualitativo e de caráter descritivo. Os dados foram coletados em outubro de 2015, na Biblioteca Pública do Estado do Paraná, que possui o acervo das edições impressas da Folha de $S$. Paulo. Realizamos cópias das matérias que faziam menção aos Jogos Paralímpicos do período citado. Selecionamos, organizamos e analisamos as edições impressas da Folha de $S$. Paulo nos anos e períodos em que foram realizadas as seguintes edições dos Jogos Paralímpicos: 1992, 1996, 2000, 2004, 2008 e 2012.

A coleta das notícias iniciou um dia antes e terminou um dia depois de cada uma das edições analisadas. As análises tomaram como base as seguintes categorias: supercrip, trivialização, infantilização e vitimização. Conforme mencionamos anteriormente, essas narrativas refletem maneiras de se falar sobre atletas paralímpicos apontadas pela literatura como peculiares à cobertura midiática sobre o esporte paralímpico e atletas com deficiência. Lemos todo o material compilado buscando localizar todas as passagens que se encaixavam em uma ou mais destas categorias. Esta classificação foi feita por diferentes pesquisadores. Ao término desta categorização, utilizamos o método de cross-checking (checagem cruzada) para verificação dos resultados. Em outras palavras, contrastamos as categorizações realizadas pelos diferentes autores e, quando houve divergência, as discutimos até atingirmos consenso. 
As passagens selecionadas foram inseridas em uma tabela Excel de acordo com a sua respectiva - ou respectivas - categoria/categorias. Na sequência, sumarizamos os conteúdos de cada notícia para facilitar o próximo passo da análise, que foi o de contrastá-los com 0 que vem descrito na literatura acerca de conteúdos/categorias similares. Para oferecermos um panorama geral numérico a respeito das categorias como um todo, no final do processo, também computamos o número total de notícias por edição.

Vale ressaltar que priorizamos as categorias supracitadas como foco de análise, porque elas tendem a reforçar, direta ou indiretamente, determinados estigmas relacionados com as pessoas com deficiência. Optamos por dar visibilidade a este tipo de problema, para que possamos gerar subsídios para evitá-lo no futuro. Uma das limitações deste recorte, no entanto, é que ele se restringe a apenas alguns aspectos da cobertura da FSP. Este recorte não permite uma visão mais geral da cobertura da FSP.

\section{APRESENTAÇÃO E DISCUSSÃO DOS DADOS}

Os dados apresentados na tabela abaixo mostram o número total de notícias encontradas em cada ano e quantas delas apresentaram características de uma ou mais das quatro categorias consideradas para a análise qualitativa dos dados.

Tabela 1 - Número de matérias categorizadas

\begin{tabular}{cccccc}
\hline Ano & $\begin{array}{r}\text { Número total de } \\
\text { matérias da FSP }\end{array}$ & Vitimização & Supercrip & Trivialização & Infantilização \\
\hline 1992 & 9 & 0 & 0 & 0 & 0 \\
1996 & 10 & 0 & 0 & 1 & 0 \\
2000 & 42 & 10 & 3 & 5 & 1 \\
2004 & 39 & 7 & 4 & 8 & 0 \\
2008 & 39 & 2 & 4 & 0 & 1 \\
2012 & 42 & 6 & 10 & 5 & 1 \\
\hline Total & 181 & $\mathbf{2 5 ( 1 3 , 8 \% )}$ & $\mathbf{2 1 ( 1 1 , 6 \% )}$ & $\mathbf{1 9 ( 1 0 , 4 \% )}$ & $\mathbf{3 ( 1 , 6 \% )}$ \\
\hline
\end{tabular}

Fonte: Dados levantados pelos autores

Os números acima demonstram que houve um aumento no número de matérias publicadas pela FSP durante os Jogos Paralímpicos ao longo dos 20 anos, podendo-se observar que no ano de 2000 houve um salto significativo na produção das notícias. Hilgemberg (2014) também apontou esta tendência de apropriação do esporte paralímpico pela mídia em seu trabalho. 0 Comitê Paralímpico Brasileiro (CPB), desde a sua criação em 1995, tem investido na visibilidade proporcionada pela mídia e tem apostado na aproximação com esta, convidando jornalistas para cobrir os Jogos, custeando, até o ano de 2012, a sua ida para eventos nacionais e internacionais do esporte paralímpico (MIRANDA, 2011; NOVAIS; FIGUEIREDO, 2010). Considerando as diferentes categorias de análise utilizadas como parte do escopo deste trabalho, a que mais apareceu nas notícias foi a vitimização, seguida de supercrip, trivialização e infantilização.

\subsection{Vitimização}

As edições de Barcelona (1992) e de Atlanta (1996) não publicaram matérias com narrativas que tratassem os atletas como vítimas. Houve, no entanto, 25 reportagens que se 
enquadram nesta categoria a partir da edição de Sydney (2000). Um exemplo da forma de expressão desta categoria aparece na matéria intitulada: "Judoca ganha bi e traz $1^{\circ}$ ouro para 0 Brasil na Austrália". Nesta matéria se conta detalhadamente a trajetória de desafios e supostos sofrimentos do atleta Antônio Tenório:

Tenório, que começou a praticar [judô] aos 8 anos, em São Bernardo do Campo, perdeu a visão do olho esquerdo em uma brincadeira com estilingue, aos 9 anos. Dez anos depois, uma infecção alérgica provocou o deslocamento da retina e Tenório perdeu a visão do olho direito (FSP, Caderno de Esporte, 22 out. 2000)

A notícia acima é construída em um tom dramático com um foco nas "perdas" de visão do atleta. Fatos como 0 acidente com 0 estilingue e a infecção que levou 0 atleta à cegueira tiveram prioridade na notícia em detrimento de seus feitos esportivos. O mesmo atleta estava participando da sua segunda Paralimpíada, em Sydney (2000), e tinha sido medalhista de ouro em Atlanta (1996). Em outra matéria, publicada no dia 23/10/2000, intitulada "Ex-roceiro dá a segunda medalha de prata para o Brasil em Sydney", a FSP noticia a conquista do atleta e logo no início conta quais foram as situações pelas quais ele passou até chegar no atletismo adaptado. A expressão "sofreu", utilizada logo abaixo, remete a um sentimento de perda e evoca a compaixão do leitor: "Foi na roça que Delfino sofreu o acidente com uma foice, que decepou parte de seu braço direito, quando tinha 17 anos" (FSP, Caderno de Esporte, 24 out.2000).

Ambas as notícias mencionadas anteriormente enfocam os atletas mais pelo ângulo de suas deficiências do que pelos seus feitos no esporte de alto rendimento. Esse tipo de abordagem, conforme aponta Hilgemberg (2014), vitimiza os atletas e remete a diferentes estigmas que marcam o sujeito como sofredor ou perdedor e não pelas suas capacidades. Esse enfoque reforça o que alguns autores chamam de "paradigma do coitadinho" (KAMA, 2004, apud HILGEMBERG, 2014, p. 50)², que, por sua vez, coloca o atleta como objeto de pena. Isto corrobora a teoria de Goffman (2012) de que as deformidades físicas podem levar à estigmatização e de que as pessoas estigmatizadas possuem uma tendência de vitimização.

As matérias analisadas publicaram também notícias que transcendem a mera vitimização dos atletas e os promovem a uma categoria de heróis. Conforme aponta Hilgemberg (2014, p. 8), "[...] a tragédia funciona como categoria introdutória para outras categorias, como 'super-deficiente' e 'exemplo de vida', uma vez que a deficiência é vista como uma tragédia que estes indivíduos têm de superar através de força de vontade e reabilitação". Essa busca de se legitimar e de se criar uma referência a ser seguida é uma estratégia fundamental para o espetáculo midiático, no qual se objetiva o maior número de consumidores.

Ressaltamos que em alguns casos os atletas fazem questão de esclarecer que não se percebem como vítimas. Na matéria intitulada "Evento que tem a participação de 4000 deficientes leva em conta a Olimpíada e seus atletas", encontramos um trecho que reflete esta realidade:

Para explicar como o esporte alterou sua vida, Roseane dos Santos [...] disse ter 'adorado' o fato de ter a perna esquerda amputada [...] 'Foi a melhor coisa da minha vida. Se eu não tivesse amputado a perna, eu não estaria aqui em Sydney', disse a atleta (FSP, Caderno de Esporte,17 out. 2000).

A atleta mencionada acima percebe 0 seu acidente como a melhor coisa que aconteceu em sua vida. A amputação de suas pernas lhe possibilitou o seu envolvimento no esporte

2 KAMA, Amit. Supercrip versus the pitiful handicapped: reception of disabling images by disabled audience members. Communications, 29 p. 447-466, 2004. 
adaptado e a sua participação nos Jogos Paralímpicos em Sydney. Este exemplo remete ao que Goffman (2012) indicou como uma forma de as pessoas estigmatizadas romperem com a realidade e criarem subterfúgios para lidar com a sua deficiência, dando outra interpretação ao caráter da identidade social que possuem. Segundo o autor, "[...] o estigmatizado pode, também, ver as privações que sofreu como uma benção secreta, especialmente devido à crença de que o sofrimento muito pode ensinar a uma pessoa sobre a vida e sobre as outras pessoas" (GOFFMAN, 2012, p. 20).

Em outro trecho, encontramos novamente um comentário valorizando a ocorrência do acidente como algo positivo: "Rosinha perdeu parte da perna esquerda após um acidente em 1990 [...] 0 acidente, porém, melhorou a vida dela [...], ex-empregada doméstica, que estudou até a quinta série" (FSP, Caderno de Esporte, -17 out. 2000).

De acordo com Marques et al. (2014), que pesquisaram a percepção de atletas de alto rendimento sobre a cobertura midiática acerca do esporte paralímpico, não há um consenso entre os atletas sobre a abordagem midiática. Parte deles concorda com a cobertura que pauta as histórias das deficiências, pois julgam que este tipo de abordagem pode se constituir em um meio importante para desmistificar o fato de que as deficiências são necessariamente algo negativo. Além disto, alguns julgam que este tipo de história pode servir para motivar outras pessoas com deficiências. Por outro lado, uma parte dos atletas entrevistados prefere ser retratada pelas suas trajetórias esportivas, pois querem ser valorizados e reconhecidos pelas suas capacidades e habilidades, e não como coitadinhos ou vítimas de suas deficiências.

\subsection{Supercrip}

Esta categoria esteve ausente das matérias veiculadas pela FSP em 1992 e 1996. Ela aparece a partir do ano 2000 em um total de 21 reportagens. Seguem alguns exemplos de supercrip que se destacaram.

Em meio a tanta desesperança, surgem exemplos de excelência em força e superação: nossos atletas paraolímpicos e sua atuação espetacular [...] Esses atletas não conquistaram somente medalhas de ouro, prata e bronze; conquistaram a autoestima e 0 agradecimento de toda uma nação. Eles não competiram contra o tempo, condições atmosféricas ou outros atletas, mas principalmente contra 0 pior adversário, o preconceito. Que os nossos outros atletas aprendam com eles que não há tempo para sentir medo (FSP, Caderno do Esporte / Painel do leitor, 27 set./2004).

A nota, publicada no painel do leitor, demonstra atletas paralímpicos tratados como verdadeiros heróis que "superaram" deficiências e preconceitos sociais, venceram a "desesperança" e se tornaram atletas de alto rendimento. Eles são retratados como exemplos para outras pessoas. $O$ modelo do supercrip ressalta a garra dos atletas no sentido de vencer dificuldades que a vida Ihes impõe. No entanto, conforme apontam Gonçalves, Albino e Vaz (2009) e Hilgemberg (2014), este modelo pode ser problemático, pois, na medida em que enfatiza a superação de dificuldades encontradas pelos atletas, os seus feitos esportivos ficam relegados a um segundo plano. Hardin e Hardin (2004) fazem ainda outras ressalvas a esse modelo. De acordo com estes autores, ao mesmo tempo em que a abordagem do supercrip pode inspirar a sociedade através de comoventes histórias de superação, também pode criar expectativas generalizantes a respeito das pessoas com deficiência. Conforme apontam estes 
autores, bem como Silva e Howe (2012), a narrativa do supercrip pode levar outras pessoas com deficiência que não possuem as mesmas condições e/ou oportunidades de superação a serem culpabilizadas, ou seja, se sentirem culpadas por não terem traçado o mesmo caminho de superações e vitórias.

Destacamos abaixo mais um exemplo de supercrip em matéria intitulada "Jogo só de vencedores". Esta matéria cita o italiano Alessandro Zanardi e o sul-africano Oscar Pistorius, denominando-os de estrelas dos JP.

\begin{abstract}
Indiscutivelmente, o vencedor Zanardi e o derrotado Pistorius eram estrelas. Mas não vibrei com nenhum desses resultados. Vejo os Jogos Paraolímpicos com olhos de admiração que só enxergam vencedores. Acredito que todos ali 0 são, simplesmente pelo que fazem. Na minha interpretação, a competição é a celebração da superação. Os resultados em si ficam em segundo plano [...] (FSP, Caderno do Esporte,10 set. 2012).
\end{abstract}

Ao enfatizar as histórias de superação dos atletas, a mídia reproduz determinados estigmas sobre eles, uma vez que reforça o sofrimento e a tragédia pessoal (HILGEMBERG, 2014), ao invés de dar destaque às suas trajetórias e conquistas esportivas. Essa perspectiva desconsidera o fato de que atletas paralímpicos são atletas de alto rendimento e que têm como objetivo triunfar nas competições das quais participam. Os seus feitos esportivos, portanto, não devem ficar em segundo plano.

Outra matéria publicada pela FSP teve a participação de um membro do Comitê Paralímpico Internacional (IPC). Trata-se da entrevista com o diretor Philip Craven, intitulada "Cartola quer melhoria de acessibilidade nos Jogos de 16":

Repórter: 'As arenas paraolímpicas estão lotadas. 0 sucesso se deve a uma campanha de marketing?'

Philip Craven: 'Houve grande mobilização da mídia e dos comitês nacionais, que tem mostrado que os Jogos são uma competição de esporte, e não para mostrar as deficiências das pessoas. Oferecemos super-humanos, humanos que são muito bons humanos. Algo até melhor que um super-herói' (FSP, Caderno do Esporte, 01 set.2012).

A fala de Craven reforça que os Jogos Paralímpicos "são uma competição de esporte" e não um show de deficiências, o que nos parece apropriado de acordo com o apontado pela literatura. A sua afirmação de que os atletas são "super-humanos" e "muito bons humanos", no entanto, pode ser problematizada. O "super" e o "bom humano" parece se referir ao fato de que os esportistas superaram inúmeros desafios em suas vidas, tanto no nível pessoal, quanto no esportivo, para chegarem a competir nos Jogos Paralímpicos. Por outro lado, o pressuposto de que atletas paralímpicos são "super" e "bons humanos" nem sempre se aplica. Como apontam Gonçalves, Albino e Vaz (2009), é preciso tomar cuidado com esse tipo de mensagem, considerando-se que alguns atletas se tornaram deficientes justamente por terem se envolvido com práticas ilícitas. Portanto, não necessariamente devem ser vistos como bons humanos, heróis ou exemplos a serem seguidos.

O modelo dos super-humanos pode também ser problematizado por outro viés. Ele pode reforçar o que tem sido criticado como "modelo médico da deficiência", que trata a deficiência a partir de parâmetros biomédicos e ajuda a construir aquilo que foi denominado por Coakley (2015) de "império da normalidade". Um império que, ao seguir padrões antropométricos e fisiológicos ideais para o corpo humano, normatiza-o e imputa-o de estigmas de eficiência 
e deficiência, podendo culpabilizar as próprias pessoas com deficiência pelos problemas e limitações por elas enfrentadas em seu cotidiano. Goffman (2012) chama atenção para o fato de que a noção de "normalidade" dos seres humanos pode ser originária de um entendimento provindo da área médica ou de organizações sociais de grande escala, como, por exemplo, os Estados-nação, que visam tratar todos os seus membros como indivíduos iguais em alguns quesitos da vida.

O modelo médico foca na deficiência, tratando-a como um problema individual que só pode ser superado através de intervenções médicas e esforço pessoal (COAKLEY, 2015). Da mesma forma, ao noticiar "super-humanos", a mídia tende a não abordar toda a rede de apoio médico, econômico, estrutural e tecnológico que esses atletas tiveram para alcançar o reconhecimento social através do esporte. Isto pode reforçar um imaginário de que os atletas se tornaram vencedores no âmbito esportivo apenas através de sua força de vontade e esforços pessoais. Esse tipo de imaginário negligencia os pressupostos do "modelo social" da deficiência, no qual se admite, conforme afirma Coakley (2015), que as deficiências se constituem e/ou se agravam na medida em que a sociedade nutre preconceitos e não garante acessibilidade para as pessoas com diferentes tipos e graus de deficiência. Na medida em que a sociedade se ajusta para otimizar as capacidades das pessoas com diferentes tipos e graus de deficiência, estas não mais precisarão ser retratadas como super-humanos.

A narrativa do supercrip sobre os atletas paralímpicos, na perspectiva de estigma para Goffman (2012), pode corresponder ao exemplo do que o autor chamou de representantes dos estigmatizados. Sobre eles "[...] são publicados, como exemplo, histórias de fundo moral sob a forma de biografias ou autobiografias que ilustram um código desejável de conduta para os estigmatizados" (GOFFMAN, 2012, p. 34). Portanto, conforme apresentamos, essa forma ambivalente em que o discurso do supercrip pode se manifestar, o caracteriza como uma estigmatização, pois:

[...] cada vez que alguma pessoa que tem um estigma particular alcança notoriedade, seja por infringir a lei, ganhar um prêmio ou ser o primeiro em sua categoria [...] todos os que compartilham o estigma da pessoa em questão tornamse subitamente acessíveis para os normais que estão imediatamente próximos e tornam-se sujeitos a uma ligeira transferência de crédito ou descrédito. Dessa maneira, sua situação leva-os facilmente a viver num mundo de heróis e vilãos da sua própria espécie, sendo a sua relação com esse mundo sublinhada por pessoas próximas, normais ou não, que lhes trazem notícias do desempenho de indivíduos de sua categoria (GOFFMAN, 2012, p. 37).

A narrativa do supercrip que apresenta os atletas como super-humanos por conseguirem, "apesar" de suas deficiências, realizar grandes feitos, pode desmistificar ou reforçar estigmas. Se, por um lado, ela desafia o estigma de que as pessoas com deficiência são frágeis e incapazes de superar determinadas barreiras e de realizar certos feitos, por outro lado, ela pode reforçar esse tipo de estigma no caso daquelas que não conseguem fazer o mesmo. Essa narrativa pode gerar uma expectativa de que todas as pessoas com deficiência podem fazer parecido caso se esforcem o suficiente (HARDIN; HARDIN, 2004; SILVA; HOWE, 2012), sem que se considerem as suas condições concretas de vida, tais como problemas de saúde, falta de apoio da família, barreiras ambientais, falta de recursos materiais e falta de acesso a oportunidades (HARDIN; HARDIN, 2004; BRITTAIN; BEACOM, 2016; COAKLEY, 2015). 


\subsection{Trivialização}

Do total de 181 matérias, 19 se enquadraram na categoria "trivialização", apresentando elementos da vida pessoal dos atletas como informações sobre namorados(as), companheiros(as), familiares e conflitos pessoais. Vejamos a seguir alguns exemplos de como essa categoria apareceu nas notícias.

Em 97, quando começou a treinar, quase abandonou o esporte por causa de um namorado. Na véspera do Mundial da Inglaterra, o namorado deu o ultimato: ou ele ou o atletismo. "Como já tinha feito minhas malas, falei pra ele fazer as dele". Rosinha não ficou muito tempo sozinha. Na Inglaterra, começou a namorar o técnico da Jamaica. "Eu o chamo de Alfredo e o conheci na festa de abertura (FSP, Caderno de Esporte, 24 out. 2000).

A passagem acima, retirada de uma matéria intitulada "Sofrimento marca a vida de medalhista", trata da vida pessoal da atleta e, especificamente, da difícil decisão que ela precisou tomar ao ter que escolher entre a sua carreira esportiva ou o seu namorado. Esta mesma temática é retomada em outra reportagem no dia 27/10/2000, com o título: "Zebra, Rosinha faz história no arremesso". Nesta nova matéria aparece também a informação de como conheceu o treinador da Jamaica, que se tornou seu namorado. As duas reportagens possuem elementos de "trivialização" tal como apontado pela literatura, uma vez que enfatizam o relacionamento amoroso da atleta e não as suas conquistas esportivas (DE LÉSÉLEUC; PAPPOUS; MARCELLINI, 2009).

Outro exemplo de trivialização pode ser visualizado na matéria intitulada: "Para-atleta desfruta de fama e dinheiro". A matéria se centra no percurso esportivo do atleta Daniel Dias e no seu crescimento financeiro. A Folha diz ter apurado que naquele momento o atleta tinha um rendimento mensal de $\mathrm{R} \$ 50$ mil: "Pela primeira vez em uma disputa mundial, Dias conseguiu pagar passagem e estadia para os pais e para a noiva acompanhá-lo durante todas as provas em Londres. [...] 'Estou realizando um sonho ao poder ter minha família aqui comigo' [...]' (FSP, Caderno de Esporte, 28 ago.2012).

$O$ atleta Daniel Dias foi retratado nas duas últimas edições da FSP relativas aos JP tanto pelos seus feitos esportivos quanto pela sua vida pessoal. A reportagem intitulada "Quinto ouro põe Daniel Dias na história" relata que o atleta se tornou o maior medalhista brasileiro das Paralimpíadas e enfatiza a sua vida pessoal: "Após a competição, Dias diz que vai se preparar para uma nova jornada. Ele se casa em novembro com Raquel Andrade, que veio até Londres para acompanhar o noivo durante as provas" (FSP, Caderno de Esporte, 8 set.2012).

A mesma informação já tinha sido publicada na reportagem do dia 28/08/2012. Ou seja, o jornal insistiu em enfatizar questões de ordem pessoal do atleta, assim como também 0 fez com a atleta Rosinha. Não identificamos reportagens que dessem ênfase para os atributos sexuais dos atletas ou para as suas roupas e maquiagens. No caso da cobertura da FSP, a maioria das matérias que se encaixaram na categoria "trivialização" fez menção à vida pessoal e aos relacionamentos amorosos dos atletas. Ou seja, ao invés de se ocupar os espaços das matérias com notícias sobre o esporte e a esportividade dos atletas, este foi ocupado com notícias alheias ao contexto esportivo. Nesta perspectiva, Goffman (2012) defende que, ao se dedicar atenção a determinadas características dos estigmatizados, pode-se destruir a possibilidade de se focar em outros atributos que poderiam facilitar a recepção deles na sociedade. 
Um dos problemas com a abordagem da "trivialização", conforme lembra Marques (2016), é que, ao se deixar em segundo plano aspectos relacionados com a prática esportiva e esportividade dos atletas, desperdiça-se a oportunidade de se desafiar determinados estigmas e de, com isto, contribuir para com a promoção da inclusão social e esportiva de pessoas com deficiência.

\subsection{Infantilização}

Constatamos que a cobertura midiática da FSP apresentou um baixo número de matérias com narrativas que infantilizam os atletas. Dentre todas as edições analisadas, encontramos apenas três reportagens que se encaixaram na categoria infantilização. Dentre elas destacamos uma passagem que foi publicada em uma das edições de Pequim (2008) e outra, em umas das edições de Londres (2012). Vejamos primeiro uma passagem da matéria do dia 14/09/2008, intitulada "Brasileiro bate recorde e leva 20 ouro", na qual a mídia fala sobre a conquista de Lucas Prado na corrida para atletas totalmente cegos (categoria T11) e cita um comentário do guia sobre a causa do sucesso do atleta: "[...] o Lucas é conhecido na Vila Olímpica como o ceguinho falador. Ele canta, brinca e, enquanto ele estiver ganhando medalhas, está ótimo" (FSP, Caderno de Esporte, 14 set.2008).

A passagem acima reproduz o termo "ceguinho" utilizado pelo guia do atleta. Este termo tende a ser pejorativo, conforme apontam guias de orientações à mídia (BRITISH PARALYMPIC ASSOCIATION, 2012; INTERNATIONAL PARALYMPIC COMMITTEE, 2014; PAPPOUS; SOUZA, 2016) sobre como se falar a respeito de atletas com deficiência. No entanto, como a expressão foi utilizada por uma pessoa próxima do atleta falando de pessoas também próximas a ele, no contexto em que foi utilizada, ela não passa uma conotação negativa. A frase "Ele canta, brinca e, enquanto ele estiver ganhando medalhas, está ótimo", no entanto, pode sugerir que 0 atleta passa o seu tempo se divertindo e se contenta com resultados pontuais. Ao publicar este tipo de mensagem, sem um enfoque no esforço que o atleta precisou empreender para se tornar um vencedor esportivo, o discurso midiático pode passar a impressão de que 0 atleta vive como uma criança que se satisfaz com conquistas passageiras, ao invés de ressaltar a sua trajetória de treinos, a infraestrutura necessária e o volume de recursos financeiros investidos para que ele se tornasse um medalhista paralímpico.

Vejamos abaixo outro exemplo emblemático de como a categoria "infantilização" apareceu, desta vez em uma das publicações acerca dos JP de Londres (2012). Trata-se de uma coluna publicada no dia 10/09/2012 intitulada "Nossa olímpica imperfeição": "Houve um anão que entrou de motoca, todo pimpão, e um russo que agradeceu ao público em linguagem de sinais [...]. E como sorriem os atletas paraolímpicos - sorriem o tempo todo, aplaudindo a si mesmos" (FSP, Caderno llustrada, 10 set.2012).

A utilização dos termos "motoca" e "pimpão" para se referir à entrada do atleta paralímpico no complexo de natação revela pouca seriedade no trato com o esportista. 0 termo "motoca" foi utilizado provavelmente porque o atleta é anão e foi associado a uma criança fazendo de conta que estava dirigindo o veículo. Neste caso, o atleta estava se utilizando de um velocípede (triciclo) para facilitar a sua locomoção devido à sua deficiência, que implica em uma limitação motora no ato de caminhar. Já a expressão "pimpão" provavelmente veio da associação da imagem do atleta a um ursinho de brinquedo com características dóceis, devido 
à sua composição física e baixa estatura por conta do nanismo. Essas são características da fragilidade e da necessidade de assistência que muitas das pessoas e atletas com deficiência possuem, mas que acabam sendo mais ressaltadas pelo discurso midiático do que as suas habilidades e capacidades atléticas.

Os dois exemplos de infantilização referidos acima podem ser associados às incertezas, identificadas por Goffman (2012), que acabam sendo geradas para as pessoas estigmatizadas, nesse caso os atletas com deficiência, sobre a posição ou o papel que eles assumem perante a sociedade. Segundo o autor, as variações de categorias às quais os estigmatizados normalmente são associados podem deixá-los inseguros se estão sendo definidos pejorativa ou positivamente. No caso dos atletas, as narrativas supracitadas podem gerar dúvidas se estão sendo definidos por quem de fato são, ou por suas deficiências e dificuldades. Considerando que durante todo o período analisado - 20 anos - encontramos apenas três reportagens que refletiram a narrativa da infantilização, o nosso estudo revela que a FSP não segue a tendência da cobertura midiática de outros países de infantilizar os atletas, conforme apontam outros estudos (DE LÉSÉLEUC; PAPPOUS; MARCELLINI, 2009; DE LÉSÉLEUC; PAPPOUS; MARCELLINI, 2010; PAPPOUS et al., 2009).

\section{CONSIDERAÇÕES FINAIS}

Esta pesquisa demonstrou um aumento da apropriação do esporte paralímpico por parte da FSP durante o período de 1992 a 2012. Ela também verificou que o jornal ainda reproduz algumas narrativas problemáticas já encontradas e tematizadas em outros estudos, sobre a forma com que a mídia vem retratando o esporte e os atletas paralímpicos. Em alguns casos ela "vitimizou" os atletas. Ela também reproduziu a narrativa do supercrip e noticiou, em algumas circunstâncias, fatos triviais sobre a vida dos atletas. Houve poucos casos de "infantilização". Se por um lado isto mostra que os atletas com deficiência são pessoas comuns que possuem namorados, família, vida financeira ativa, etc., ao se enfocar em notícias como estas, a mídia perde a oportunidade de informar sobre as modalidades paralímpicas e de mostrar as trajetórias esportivas e capacidades atléticas dos desportistas.

Os modos de agir da sociedade com relação ao esporte e os modos em que ele é compreendido são mediados, principalmente, pelos meios de comunicação de massa (PIRES, 2002). Tendo isto em vista, este estudo oferece alguns indícios para uma reflexão crítica sobre os modos como percebemos as pessoas com deficiência e sobre os modos como a mídia neste caso da FSP, uma das mídias de maior circulação no país - ajuda a produzir e ao mesmo tempo reproduz estas percepções. Os dados desta pesquisa podem servir como subsídios para melhor compreendermos como o processo de midiatização e espetacularização do esporte paralímpico no Brasil está ocorrendo, em parte, influenciado por estigmas sociais comumente associados às pessoas com deficiência.

Esta pesquisa se restringiu à investigação de algumas narrativas apontadas pela literatura como problemáticas na cobertura midiática do esporte paralímpico: "supercrip", "vitimização", "infantilização" e "trivialização". Diante desta limitação, reconhecemos que são necessários outros estudos que abordem as características gerais da cobertura midiática sobre o esporte paralímpico, bem como estudos que investiguem a cobertura dos Jogos Paralímpicos Rio/2016, realizados após a finalização de nossa coleta e análise de dados. 
Considerando que a mídia pode exercer um papel importante na construção de representações sociais mais positivas acerca das pessoas com deficiência, mostrando as capacidades destas pessoas, quando elas encontram condições concretas de desenvolver suas potencialidades, apontamos também a necessidade de mais estudos que envolvam diferentes veículos e meios de comunicação de massa (programas televisivos e portais de notícias vinculados a diferentes grupos midiáticos), assim como mídias sociais (Facebook, Instagram e Twitter), dado o alcance destes meios. Estudos de recepção também se fazem necessários, pois podem dar voz aos indivíduos que possuem deficiência ou não, tendo 0 potencial de gerar subsídios para a qualificação da mídia em sua cobertura do esporte e dos atletas paralímpicos. Pesquisas como esta também podem ajudar a revelar questões esclarecedoras sobre as relações que se estabelecem entre a mídia e o esporte paralímpico, gerando conhecimentos críticos para uma educação sobre as mídias, tendo em vista a sua importância enquanto ferramenta educacional.

\section{REFERÊNCIAS}

BRITTAIN, lan; BEACOM, Aaron. Leveraging the London 2012 Paralympic Games: what legacy for people with disabilities? Journal of Sport and Social Issues, v. 40, n. 6, p. 499-521, 2016.

BRITISH PARALYMPIC ASSOCIATION. Guide to Reporting on Paralympic Sport. Reino Unido, ParalympicsGB, 2012. Disponível em: <http://paralympics.org.uk/uploads/documents/imported/ ParalympicsGB Guide to Reporting on Paralympic Sport - June 2012.pdf>. Acesso em: 14 set. 2016.

COAKLEY, Jay. Sport in society: issues and controversies. 11. ed. New York: McGraw-Hill, 2015.

DE LÉSÉLEUC, Eric. International perspectives on media and the Paralympics: some ways for future researches. In: GILBERT, Keith; SCHANTZ, Otto. (Eds.). Heroes or Zero's: the media's portrayal of paralympic sport. New York: Common Ground Publishing, 2012. p. 7-35.

DE LÉSÉLEUC, Eric; PAPPOUS, Athanasios; MARCELLINI, Anne. La cobertura mediática de las mujeres deportistas con discapacidad: Análisis de la prensa diaria de cuatro países europeos durante los Juegos Paralímpicos de Sídney 2000. Apunts, Educación Física y Deportes, v. 97, n. 3, p. 80-88, 2009.

DE LÉSÉLEUC, Eric; PAPPOUS, Athanasios; MARCELLINI, Anne. The media coverage of female athletes with disability: Analysis of the daily press of four European counties during the 2000 Sidney Paralympic Games. European Journal for Sport and Society, v. 7, n. 3-4, p. 283-296, 2010.

DUNCAN, Margaret Carlisle. Gender Warriors in Sport: Women and the Media. In: RANEY, A. A.; BRYANT, J. (Eds.). Handbook of Sports and Media. New Jersey: Lawrence Erlbaum Associates, 2006. p. 247-269.

FIGUEIREDO, Tatiane Hilgemberg. Gênero e Deficiência: uma análise da cobertura fotográfica dos Jogos Paralímpicos de 2012. Estudos em Jornalismo e Mídia, v. 11, n. 2, p. 484-497, 2014.

GOFFMAN, Erving. Estigma: notas sobre a manipulação da identidade deteriorada. 4. ed. Rio de Janeiro: LTC, 2012. 
GONÇALVES, Gisele Carreirão; ALBINO, Beatriz Staimbach; VAZ, Alexandre Fernandez. O herói esportivo deficiente: aspectos do discurso em mídia impressa sobre o Parapan-Americano 2007. In: PIRES, Giovani De Lorenzi. (Org.). “Observando” o Pan Rio/2007 na mídia. Florianópolis: Tribo da Ilha, 2009. p. 149-167.

HARDIN, Brent; HARDIN, Marie. Conformity and conflict: Wheelchair athletes discuss sport media. Adapted Physical Activity Quarterly, v. 20, n. 3, p. 246-259, 2003.

HARDIN, Marie; HARDIN, Brent. The "Superscrip" in sport media: Wheelchair athletes discuss hegemony's disabled hero. SOSOL: Sociology of Sport Online, v. 7, n. 1, p. 1-14, 2004.

HILGEMBERG, Tatiane. Do Coitadinho ao Super-herói Representação social dos atletas paraolímpicos na mídia brasileira e portuguesa. Ciberlegenda, n. 30, p. 48-58, 2014.

INTERNATIONAL PARALYMPIC COMMITTEE. Guide to reporting on persons with an impairment. Bonn, International Paralympic Committee, 2014. Disponivel em: <https://www.paralympic.org/sites/default/files/ document/14102710352784420141031+Guide+to+reporting+on+persons+with+an+impairment. pdf>. Acesso em: 14 set. 2016.

MARQUES, Renato Francisco Rodrigues et al. A abordagem midiática sobre o esporte paralímpico: 0 ponto de vista de atletas brasileiros. Movimento, v. 20, n. 3, p. 989-1015, 2014.

MARQUES, Renato Francisco Rodrigues. A contribuição dos Jogos Paralímpicos para a promoção da inclusão social: o discurso midiático como um obstáculo. Revista Brasileira de Educação Física e Esporte, n. 108, p. 87-96, 2016.

MARTÍN-BARBERO, Jesús. Dos meios às mediações: comunicação, cultura e hegemonia. Rio de Janeiro: Editora UFRJ, 2009.

MIRANDA, Tatiane Jacusiel. Comitê Paralímpico Brasileiro: 15 anos de história. Campinas: Universidade Estadual de Campinas, 2011.

NOVAIS, Rui Alexandre; FIGUEIREDO, Tatiane Hilgemberg. A visão bipolar do pódio: olímpicos versus paraolímpicos na mídia on-line do Brasil e de Portugal. Logos 33, v. 17, n. 2, p. 78-89, 2010.

PAPPOUS, Athanasios et al. La representación mediática del deporte adaptado a la discapacidad en los medios de comunicación. Ágora para la EF y el Deporte, n. 9, p. 31-42, 2009.

PAPPOUS, Athanasios; SOUZA, Doralice Lange De. Guia para a mídia: Como cobrir os Jogos Paralímpicos Rio 2016. 2016. Disponível em: < http://www.cpb.org.br/documents/20181/0/ Guia+para+a+mídia+Rio+2016/a26cb813-1e28-4e71-84d8-bd93ea39308c>. Acesso em: 1‥ nov. 2017.

PEREIRA, Olga; MONTEIRO, Inês; PEREIRA, Ana Luísa. A visibilidade da deficiência: uma revisão sobre as representações sociais das pessoas com deficiências e atletas paraolímpicos nos media impressos. Revista da Faculdade de Letras da Universidade do Porto, v. 22, p. 199-217, 2011.

PIRES, Giovani De Lorenzi. Educação Física e o discurso midiático: abordagem críticoemancipatória. ljuí: Unijuí,2002 . (Coleção Educação Física).

SCHELL, Lea Ann; DUNCAN, Margaret Carlisle. A Content Analysis of CBS's Coverage of the 1996 Paralympic Games. Adapted Physical Activity Quarterly, v. 16, p. 27-47, 1999.

SILVA, Carla Filomena; HOWE, P. David. The (In)validity of Supercrip Representation of Paralympian Athletes. Journal of Sport \& Social Issues, v. 36, n. 2, p. 174-194, 2012. 
Agradecimentos: às contribuições das estudantes de graduação da licenciatura em Educação Física Fernanda Anselmo e Ane Ramiro, no processo de coleta e organização dos dados e às orientações do professor doutor Athanasios Pappous, da University of Kent, na idealização deste projeto de pesquisa.

\section{Apoio:}

parte dos autores contou com apoio financeiro, em formato de bolsa de estudos de pósgraduação, da Coordenação de Apoio ao Aperfeiçoamento de Pessoal de Ensino Superior (Capes). 